\title{
Design of a Solar PV based Hybrid AC mini grid System with Load Dispatch Centre for an Off- grid Area of Bangladesh
}

\author{
Al-Amin Shuvo', Md. Ziaul Islam², Dr. Md. Shawkut Ali Khan ${ }^{3}$ \\ Lecturer, Electrical and Electronic Engineering Department, City University, Dhaka, Bangladesh ${ }^{1,2}$ \\ Professor, Mechanical Engineering Department, City University, Dhaka, Bangladesh ${ }^{3}$
}

\begin{abstract}
Bangladesh is a developing country with a large population and a smaller area. A large area is still uncovered either by grid electricity or by the electricity generated from renewable sources. Still solar home system is very popular in Bangladesh with some unavoidable constraints. From this perspective, a hybrid AC mini grid system based on solar PV has been designed for an off-grid region of Bangladesh. A survey was held on the rural people of that off-grid area to gather different types of information to design a feasible hybrid AC mini grid system. Cost analysis has been done to set-up the mini grid depending on the information using HOMER software. Furthermore, as it is a hybrid system, others necessary parts have also been prepared to design a complete AC mini grid system. Some indispensable parts of AC mini grid are centralized solar plant, Charge controller, transmission line, energy meter for every consumer and a common Load Dispatch Center (LDC) to control the total system that has been introduced in this paper. Finally, a special grid-tie inverter is designed to hook up the propose system with future National grid. Moreover, a power line carrier communication has been established in order to control every consumer from LDC which can ensure a reliable mini grid system for the off grid area in this paper. This kind of efficient \& reliable AC mini grid can be a realistic solution for the off-grid areas of Bangladesh.
\end{abstract}

Keywords: AC mini grid, HOMER, hybrid system, LDC.

\section{INTRODUCTION}

Renewable energy is becoming popular day by day due to fast depletion of conventional fuels. Statistics manifest that quantity of consumption of fossil fuel is increasing at a higher rate. The production of total electricity cannot fulfil the demand of the consumers adequately. Therefore, many Government and non-government organizations start to establish different types of renewable energy project as an alternate of fossil fuel. Out of all the renewable energy sources, solar energy is the leading one. It has become one of the most popular forms of renewable energy. In the beginning, solar home system was introduced in the rural area of Bangladesh. However, there are some major challenges and constraints had been found in that rural area which de-creased the interest of installing solar home system among the rural community [1]. Consequently, solar energy would be a steadfast decision for designing an AC mini grid sys-tem. Not only that, fortunately, the location of Bangladesh is quite suitable for harnessing solar energy and due to declining price of PV panels, both in the off grid and grid connected areas of Bangladesh, Solar Home System (SHS) is getting popular very rapidly. Therefore, solar energy was taken as the main resource to provide electricity and to design the ac mini grid for a remote village in Madaripur district of Bangladesh. The whole system of hybrid ac mini-grid has been designed considering the data collected from that selected village.

Since it is a system with battery backup, a charge controller having conspicuous features is designed for the battery. An intelligent energy meter with salient features has been designed and fabricated for the proposed system, which is capable to communicate with the load dispatch centre (LDC).According to the design, every consumer will have an energy meter so that LDC will have an overall control on all of the consumers. A communication circuit is designed through power line to make a communication between LDC and energy meter. It can help to pass the communication signal with different frequency through the same transmission line where normally $220 \mathrm{~V}, 50 \mathrm{~Hz}$ electrical signal travels. By using the powerline carrier communication, a complete control on the consumer can be introduced as a part of this proposed AC mini grid. In addition, it is expected that within next few years, a national grid line will be in that area to serve electricity to the rural people. Therefore, it is essential to design a grid-tie inverter to hook up with the national grid for the upcoming future. Otherwise, this project may be destroyed economically. 
International Journal of Innovative Research in Electrical, Electronics, Instrumentation and Control Engineering

Vol. 9, Issue 7, July 2021

\section{DOI 10.17148/IJIREEICE.2021.9721}

In addition, it is expected that within the next few years, a national grid line will be in that area to serve electricity to the rural people. Therefore, it is essential to design a grid-tie inverter to hook up with the national grid for the upcoming future. Otherwise, this project may be destroyed economically. To avoid this situation, a grid-tie inverter is designed which is different from regular inverter. It comprised with a voltage regulator circuit which is very beneficial for the fluctuate output of PV. Subsequently, cost analysis of solar PV systems has been done using a computer-based software. The software calculates the voltage and battery backup for different systems. However, a feasible system is shown in this paper from the simulation based on the Cost of Energy (COE) for per unit energy.

\section{METHODOLOGY}

The objective of this paper is to design a solar PV based hybrid ac mini grid system for a remote area of Bangladesh. The following four steps were followed to accomplish the project.

i) Selection of Suitable Remote Area

ii) Data Collection

iii) System Design

iv) Cost Analysis

\section{A. Selection of Suitable Remote Area}

The first step was to find a remote area for the hybrid ac mini-grid, which is completely disconnected from the grid line electricity, where people are using solar panel or other oil based lamps in the night. An off-grid village was found called 'BabuMolla Kandi' and the population of the village is around twelve hundred. It is situated in "Madaripur" district, the P.O is "Kathalbari" and the P.S is "Shibchar". The Latitude is 23.395912 and the longitude is 90.192430 respectively [2].

\section{B. Data Collection}

A survey was done in 'Babu Molla Kandi' village to collect the data from the local people such as their current solar panel size, battery size, daily energy demand, future demand, number of electrical gadgets, size of loads, family members, monthly income, problems and suggestions with regard to present solar home system etc. About 100 houses were visited and various aspects of the solar home system installed in the village were discussed with the locals. Furthermore, data was collected on some local shops, which use solar panels for generation of electricity. At one stage of the survey, group discussion was arranged with local people to assess their feelings on the solar home system. The group of people invited for discussion was a mixture of literate and illiterate persons. A person who can write his/her own name is termed as

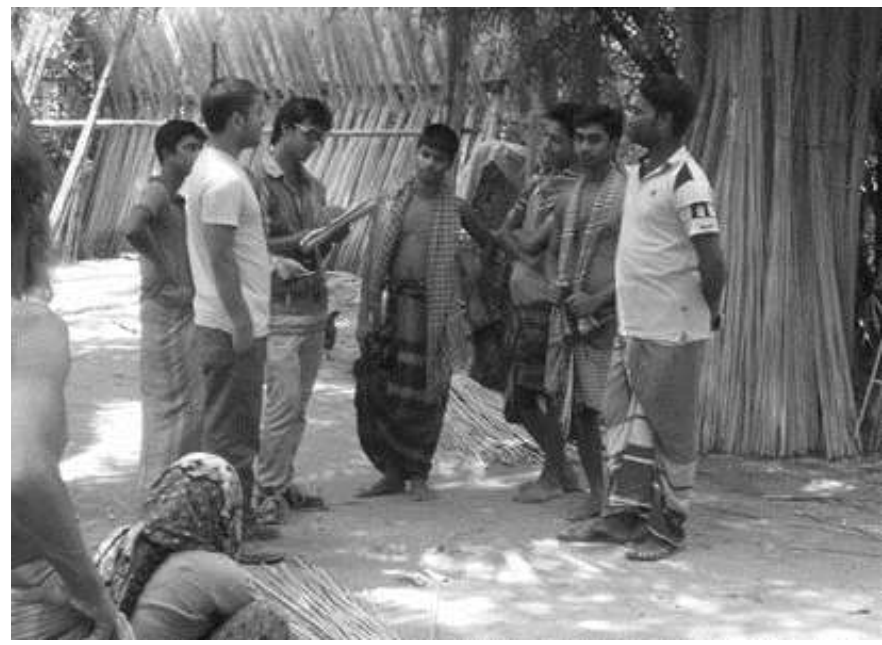

Fig. 1 Data collection from the rural people.

literate and who cannot write his/her own name is categorized as illiterate for the survey. Photographs of panels and other accessories of Solar Home System (SHS) were taken to focus the problems faced by the users of SHS. Moreover, an overall scenario of solar energy of that particular area was sketched. Through data collection and observation of the existing SHS, a clear idea was developed about the present status of solar home system in the households, the difficulties faced by them. 
International Journal of Innovative Research in

Electrical, Electronics, Instrumentation and Control Engineering

Vol. 9, Issue 7, July 2021

DOI 10.17148/IJIREEICE.2021.9721

\section{System Design}

The overall prospects, challenges and constraints of the SHS were tried to figure out using the data collected from the selected remote area. These important factors help to design a reliable mini grid for the remote area. For instance, the Solar PV system for both the system voltage $48 \mathrm{~V} \& 220 \mathrm{~V}$ were designed from the data. The entire schematic diagram was drawn using Proteus Design Suite soft-ware tool.

D. Cost Analysis

After that, the cost of solar PV system with others part analyzed using the Homer software [3]. This software calculates the cost for different system voltage and battery backup. HOMER's optimization and sensitivity analysis algorithms allow to evaluate the economic and technical feasibility of a large number of technology options and to account for variations in technology costs and energy resource availability. It modeled both the technical and economic factors involved in the project. It provided an important overview that compares the cost and feasibility of different configurations. However, a feasible system found from the simulation based on the Cost of Energy (COE).

\section{AC MINI GRID DESIGN}

The main components of the proposed system are shown in the following figure. This hybrid ac mini-grid based on solar power comprises with centralized solar plant, charge controller, energy storage device, and generator and transmission line to transmit power to consumer, energy meter and Load Dispatch Center (LDC) to control the total system using power line as a carrier for communication. In addition, inverter is designed to make link with the national grid. From the cost comparisons of different combinations, the most economical system is selected which ensures power supply continuity [4].

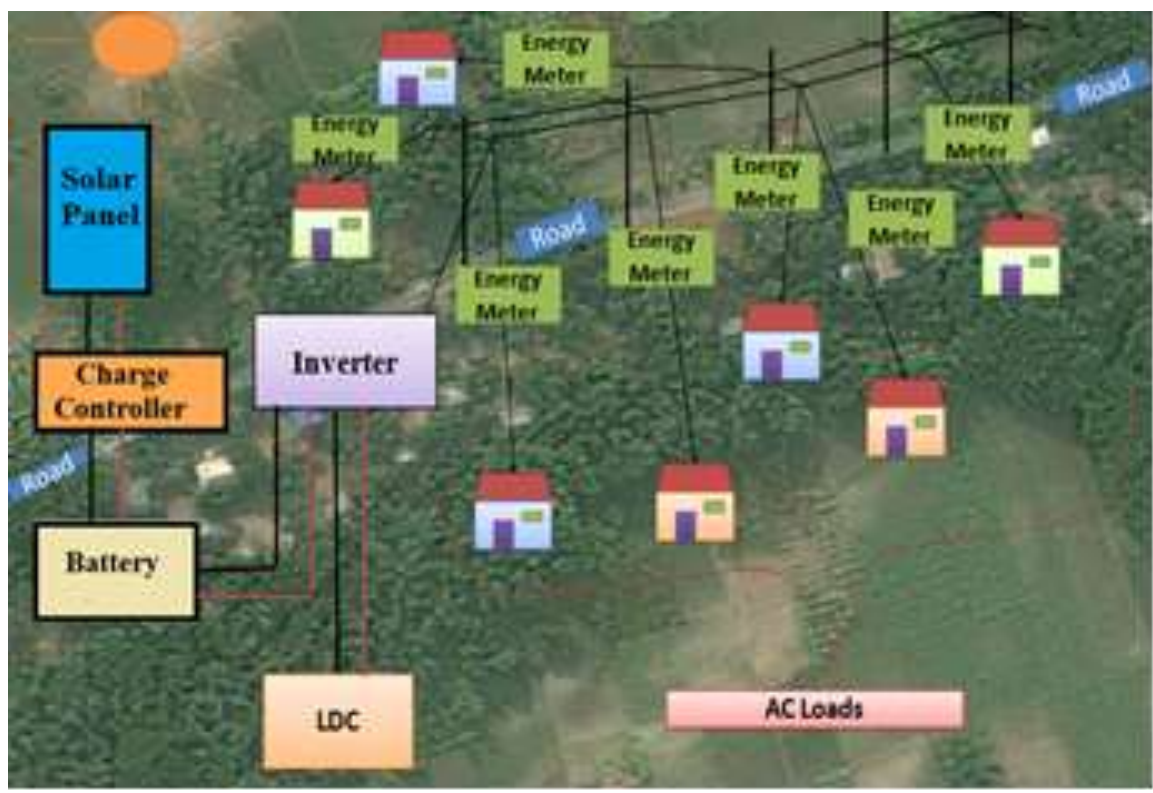

Fig. 2 Major components of AC mini grid.

A. Solar PV Design

Total connected load and energy demand per day estimated from the survey on the remote area in Madaripur district is $18.3 \mathrm{~kW}$. Considering 85 percent load factor and diversity factor 1.1 :

New total load $=($ total $\mathrm{kW} \times$ load factor $) /$ diversity factor $=(18.3 \times 0.85) / 1.1=14.14 \mathrm{~kW}$

Total Energy $=14.146 \times 24=340 \mathrm{~kW}$-h/day

Considering Inverter loss,

Total Required Energy $=340 / 0.85=400 \mathrm{~kW}-\mathrm{h} /$ day

For $48 \mathrm{~V}$ system voltage,

Using PV module $12 \mathrm{~V}, 3.5 \mathrm{~A}$ ratings and considering losses and safety factor,

Total A-h/day $=((400 \mathrm{kWh} /$ day $) \times 1.2) / 48=10000 \mathrm{Ah} /$ day

Total PV array current $=($ Total Ah/day $) /($ Sunshine hours/day $)=10000 / 6=1666.66 \mathrm{~A}$

No. of module in parallel $=$ Total PV current $/$ module operating current $\times$ de-rate factor $=1666.66 /(3.5 \times 0.9)=529$ panels

No. of module in series $=$ system nominal voltage/module nominal voltage $=48 / 12=4$ panels

Battery capacity $=(($ total daily Ah/day $) \times$ Reserved time $) / \mathrm{DOD}=(10000 \times 3) / 0.8=37500 \mathrm{Ah}$ 
International Journal of Innovative Research in Electrical, Electronics, Instrumentation and Control Engineering

Vol. 9, Issue 7, July 2021

DOI 10.17148/IJIREEICE.2021.9721

Using battery $12 \mathrm{~V}, 200$ Ah ratings

No. of battery in parallel $=$ required battery capacity/capacity of selected battery $=37500 / 200=188$ batteries

No. of battery in series $=$ system nominal voltage/battery voltage $=48 / 12=4$ batteries. From the similar calculation, the number of series, parallel panels and batteries of the solar PV have been determined for the $220 \mathrm{~V}$ systems and the summery of the both system voltage is shown in Table I.

TABLE I REQUIRED PV MODULES AND BATTERY FOR SOLAR PV DESIGN.

\begin{tabular}{|l|l|l|}
\hline System Parameters & 48V System & 220V System \\
\hline Rating of PV Module & $12 \mathrm{~V}, 3.5 \mathrm{~A}$ & $12 \mathrm{~V}, 3.5 \mathrm{~A}$ \\
\hline No. of Parallel Module & 529 & 116 \\
\hline No. of Series Module & 4 & 19 \\
\hline Rating of Battery & $12 \mathrm{~V}, 200 \mathrm{Ah}$ & $12 \mathrm{~V}, 200 \mathrm{Ah}$ \\
\hline No. of Parallel Battery & 188 & 41 \\
\hline No. of Series Battery & 4 & 19 \\
\hline
\end{tabular}

\section{B. Charge Controller}

A charge controller limits the rate at which electric current is added to or drawn from electric batteries. It prevents overcharging and may prevent against overvoltage, which can reduce battery performance or lifespan, and may pose a safety risk. It may also prevent completely draining ("deep dis-charging") a battery, or perform controlled discharges, depending on the battery technology, to protect battery life. A microcontroller based charge controller is designed and shown in Fig. 3.

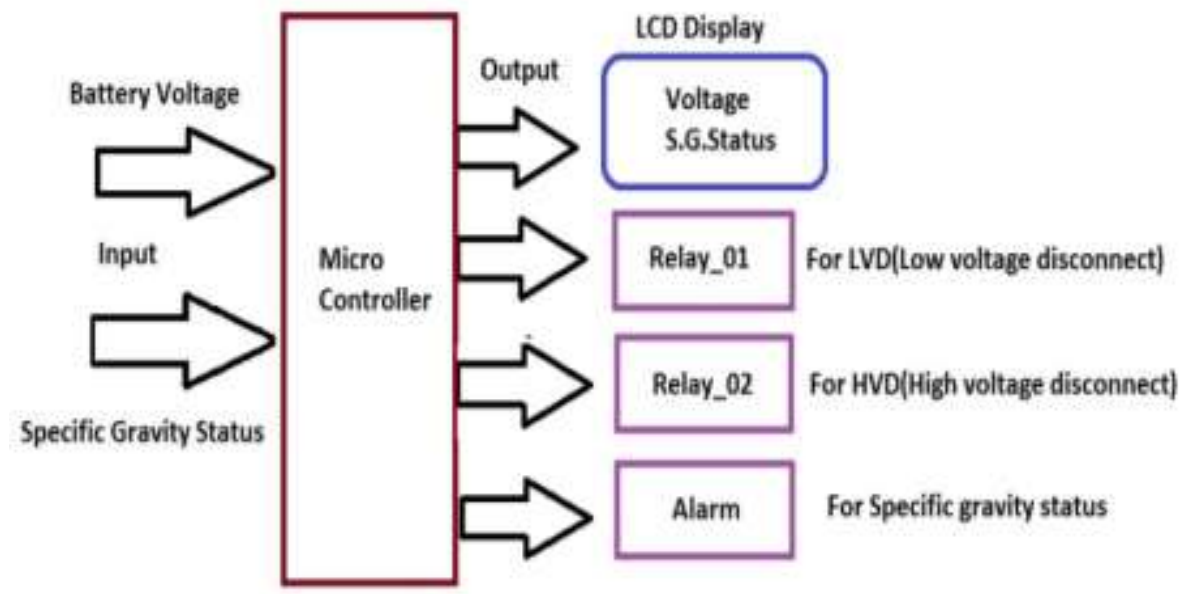

Fig. 3 Block diagram of charge controller.

The micro-controller takes the battery voltage and the output voltage of specific gravity sensor as inputs. If the battery voltage is higher than a certain level, then controller gives an alarm and disconnects the battery from the solar panel. This is known as high voltage disconnects (HVD). On the other hand, if the battery voltage goes down and crosses the minimum voltage level, controller gives another alarm and dis-connects the loads from the battery. This one is known as low voltage disconnects (LVD) [5]. Another task of this controller is to show the specific gravity status in every second. It takes the output voltage from the sensor and shows the continuous status of the battery in LCD display. If the status is below or above the certain range, controller gives an alarm. The circuit diagram of charge controller is shown in Fig. 4.

\section{Transmission Line Design}

Selected Conductor: ACSR Thrasher Conductor has been chosen from various types of aluminum conductors for transmission line design to reduce the line loss [6]. Its specifications are given below:

- Diameter: $0.045771 \mathrm{~m}$

- $\quad \mathrm{R}$ at 27C: $0.0266 \mathrm{ohm} / \mathrm{km}$

- Ampacity: $1875 \mathrm{~A}$

Total estimated connected load is $18.3 \mathrm{~kW}$. Therefore, the current passing through transmission line for $220 \mathrm{~V}$ systems will be, $\mathrm{I}=18.3 \mathrm{~kW} / 220 \mathrm{~V}=83.13 \mathrm{~A}$

Line loss will be, $\mathrm{P}=83.132 \times 0.0266=184.05 \mathrm{~A}$ per $\mathrm{km}$ 
IJIREEICE

International Journal of Innovative Research in Electrical, Electronics, Instrumentation and Control Engineering

Vol. 9, Issue 7, July 2021

DOI 10.17148/IJIREEICE.2021.9721

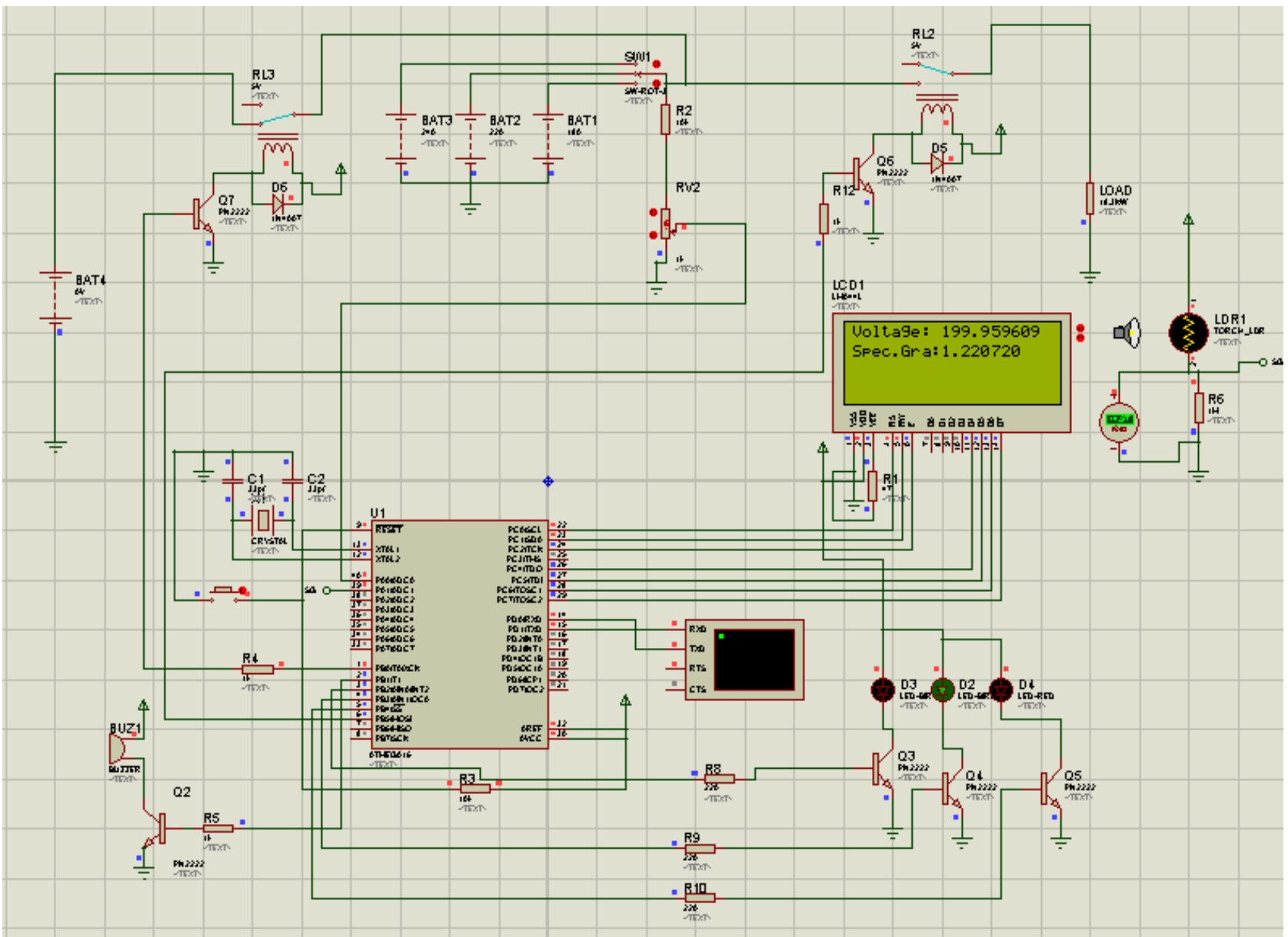

Fig. 4 Schematic design of charge controller.

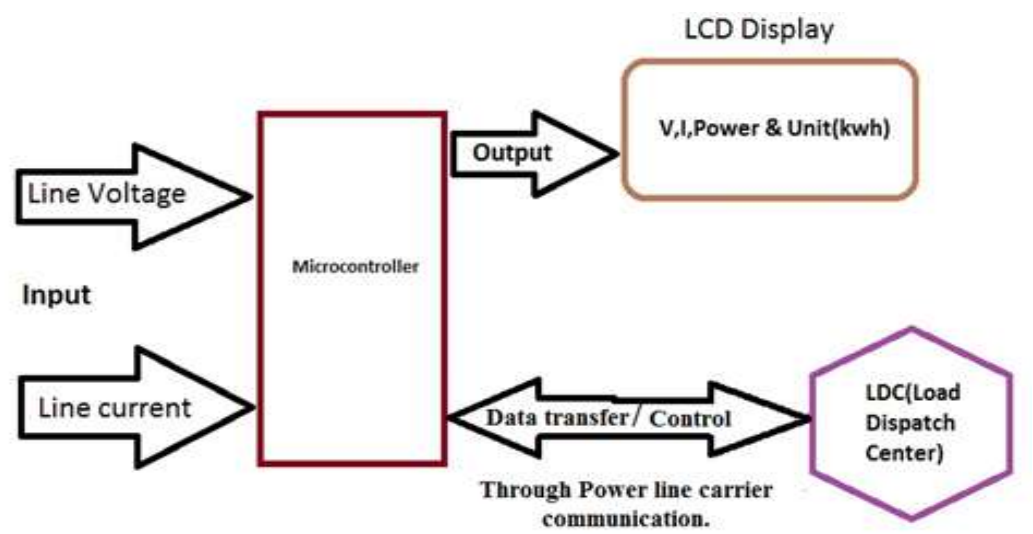

Fig. 5 Block diagram of the digital energy meter.

\section{Digital Energy Meter}

An electricity meter or energy meter is a device that measures the amount of electric energy consumed by a residence, business or an electrically powered device. Electricity meters are typically calibrated in billing units, the most common one being the kilowatt-hour [kWh]. A periodic reading of electricity meters establishes billing cycles and energy used during a cycle. Block diagram of the digital energy meter is shown in Fig. 5. A microcontroller has been used to design the energy meter. Line voltage and line current act as inputs in it. Line cur-rent is measured using Hall Effect sensor. After taking the value of the line voltage and current, it does necessary calculation to find the cumulative energy in kilowatt-hour (KWh). It checks the consumer loads based on power and the short circuit in every seconds [7]. When the 
International Journal of Innovative Research in Electrical, Electronics, Instrumentation and Control Engineering

Vol. 9, Issue 7, July 2021

DOI 10.17148/IJIREEICE.2021.9721

consumer's power crosses a certain limit, the meter gives an alarm for 10 seconds. If the consumer reduces the number of load within 10 seconds, the alarm will stop line current, which flows normally.

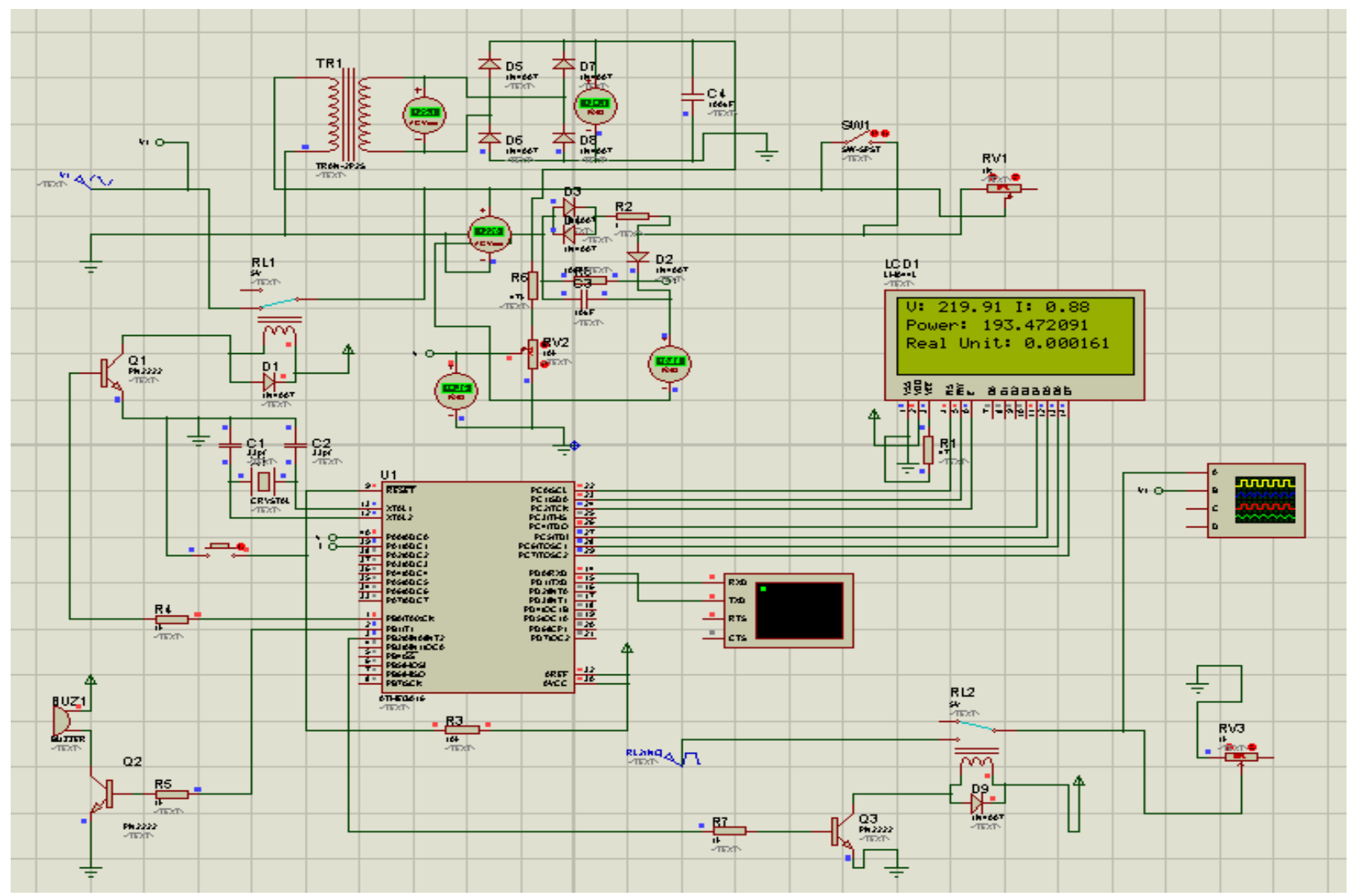

Fig. 6 Schematic design of a digital energy meter in Proteus.

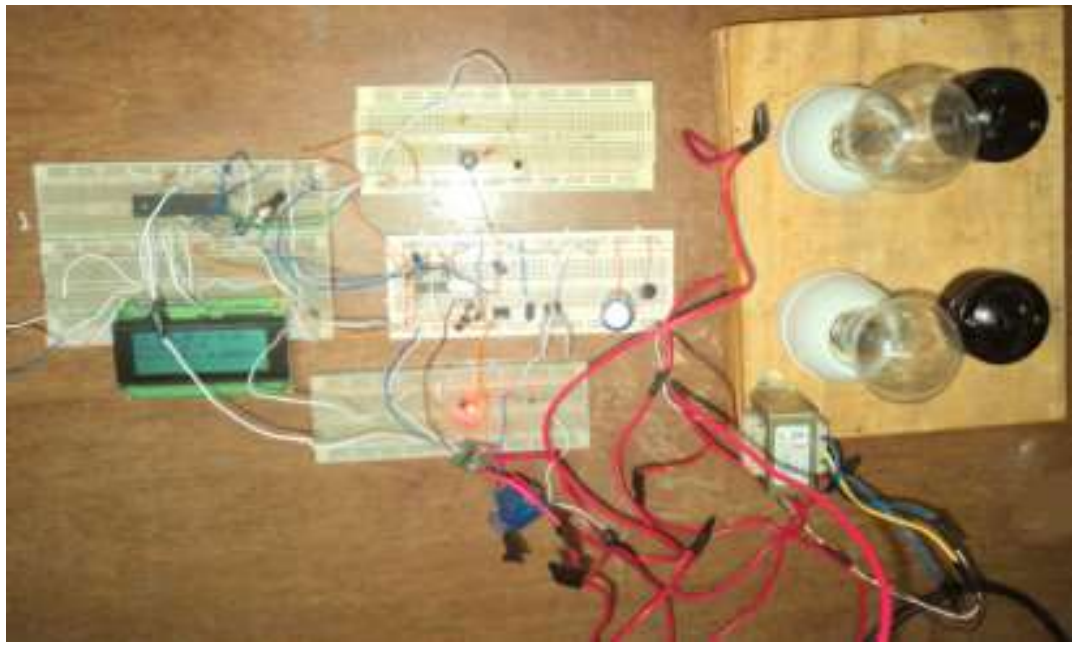

Fig. 7 Designed energy meter.

However, if consumer does not reduce the load with-in this time range, the energy meter will disconnect the load by using a relay from the line and sends a signal information to the Load dispatch center (LDC) that the consumer is disconnected. Another task of the meter is to check the short circuit; if there is any short circuit, meter will give an alarm for 10 seconds but disconnect the consumer from the line instantly by using another relay. Like before, it will send a signal to the LDC and it indicates the consumer is disconnected due to short circuit. An Energy Meter was implemented in hardware using the diagram of Fig. 6, which fulfills the above-discussed features. Implemented hardware is shown in Fig. 7. 
International Journal of Innovative Research in Electrical, Electronics, Instrumentation and Control Engineering

Vol. 9, Issue 7, July 2021

DOI 10.17148/IJIREEICE.2021.9721

\section{E. Power Line Carrier Communication}

Power-line communication (PLC) carries data on a conductor that is used simultaneously for AC electric power transmission or electric power distribution to consumers. In this paper, a communication system is designed between Load Dispatch center (LDC) and energy meter (at consumer end) through the transmission line.

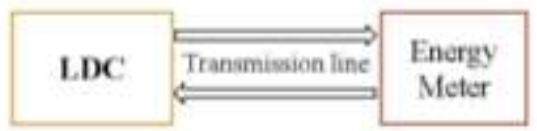

Fig. 8 Communication between LDC and the energy meter through transmission line.

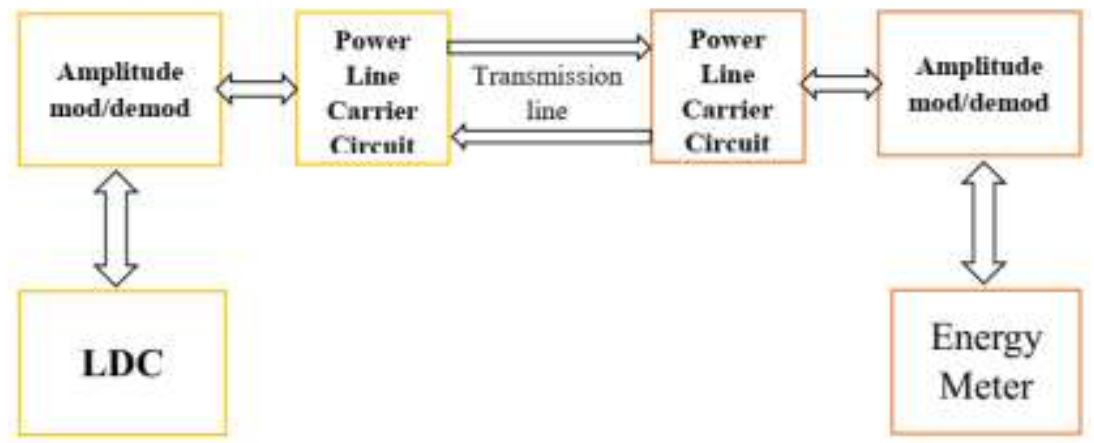

Fig. 9 Basic block diagram of power line communication.

The basic block diagram to establish a communication between Energy meter and LDC is shown in Fig. 9. First, energy meter generates a signal according to the information, which is different from the AC $50 \mathrm{~Hz}$ signal, which is challenging [8]. After that, there is a modulation block where the signal is modulated according to the amplitude with a high carrier frequency. This modulated signal passes through the next block called power-line carrier circuit where a transformer is used to isolate the energy meter side and the high voltage transmission line. At the receiver end, there is another powerline circuit block to isolate the signal and send it to the demodulation block. In the demodulation block, this signal is demodulated by the same carrier frequency. A band pass filter exists in the demodulator block that can filter out the communication signal safely from the main $50 \mathrm{~Hz}$ signal.

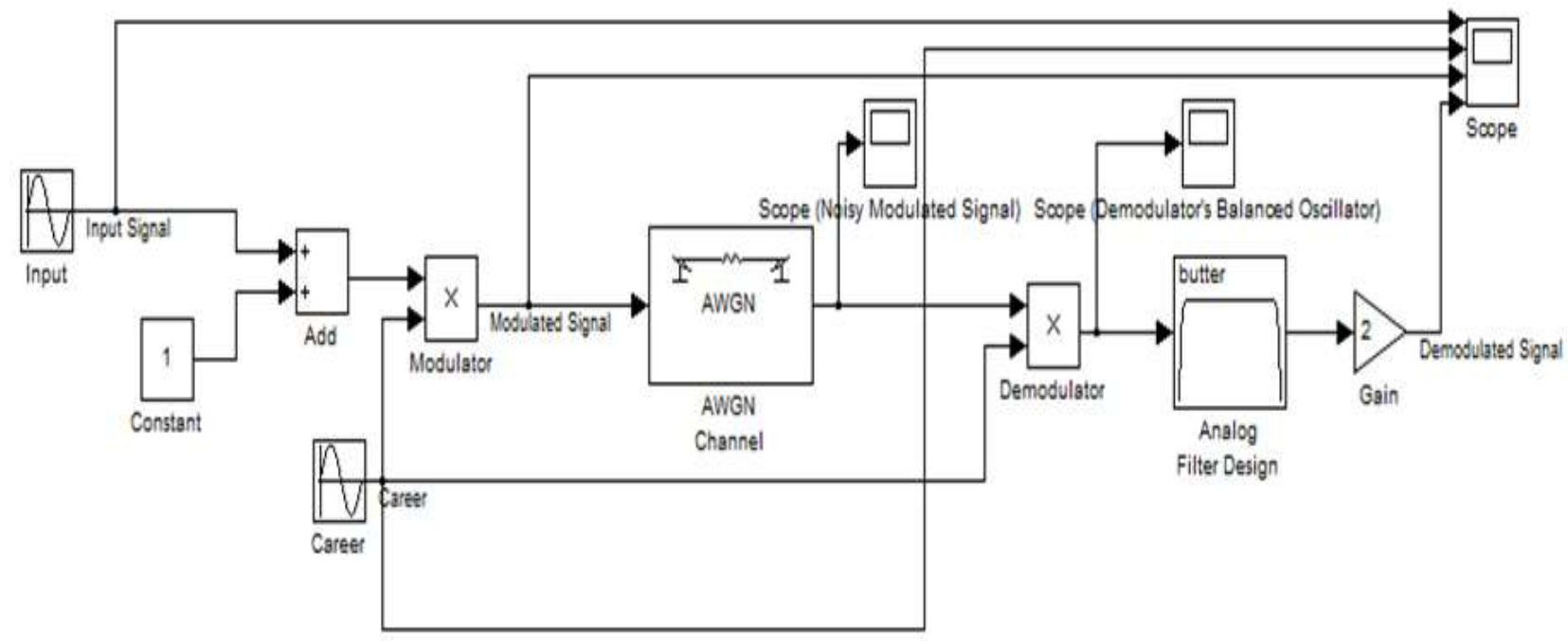

Fig. 10 Amplitude modulation/demodulation in Simulink.

Finally, LDC gets the information from the energy meter as a signal according to the occurrence happened at the energy meter. LDC gets different frequencies signal for different occurrence. Moreover, LDC can send necessary signal to the energy meter through the same trans-mission line and same topology. Amplitude modulation/demodulation block shows the modulating/demodulating part of the power-line carrier communication. Its Simulink diagram is shown in Fig. 10 \& 11. 
International Journal of Innovative Research in Electrical, Electronics, Instrumentation and Control Engineering

Vol. 9, Issue 7, July 2021

DOI 10.17148/IJIREEICE.2021.9721

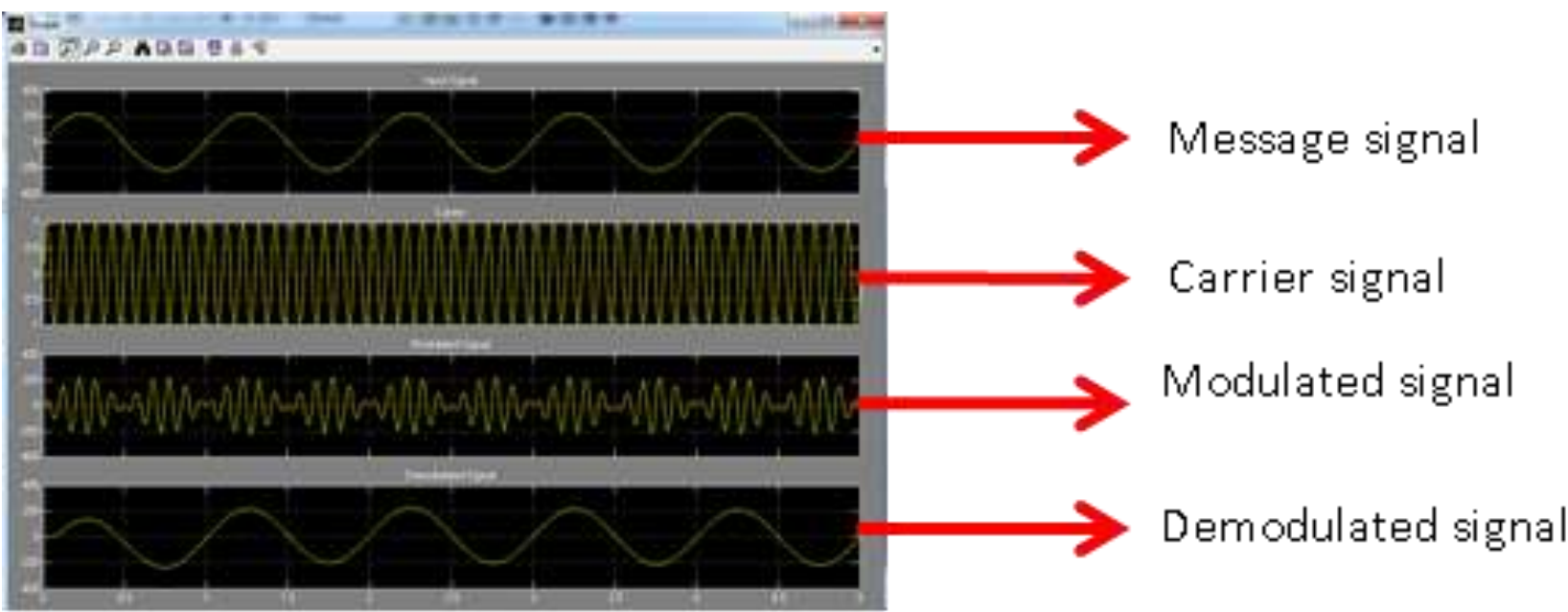

Fig. 11 Message signal and the demodulated signal in the same scope.

\section{F. Grid-tie Inverter}

A grid-tie inverter is a power inverter that converts direct current (DC) electricity into alternating current (AC) with an ability to synchronize to interface with a utility line. There are three important criteria of grid-tie inverter that should be fulfilled to synchronous mini grid with the national grid. These three criteria are same voltage level, same frequency and same phases. A design of grid-tie inverter is presented in this paper, which is capable to hook-up the mini grid line with the national grid, control the DC output voltage of solar panel, synchronize with the national grid and save the mini grid economically. Block diagram and circuit diagram are given in Fig.12 and Fig.13 respectively.

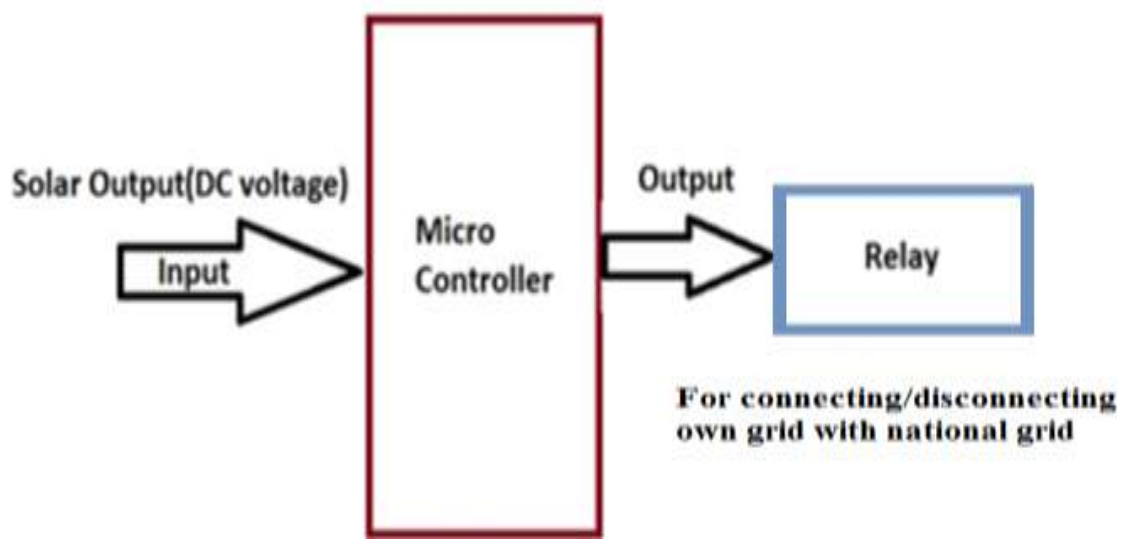

Fig.12 Block diagram of grid-tie inverter.

The grid tie inverter designed for AC mini grid systems takes the solar output DC voltage as its input. Since the out-put of the solar panel is a variable DC voltage, a voltage regulating circuit has been used to fix the voltage for a certain level [9]. If the range of input voltage is $30 \mathrm{~V}$ to $60 \mathrm{~V}$, then the voltage regulator can supply $48 \mathrm{~V}$ DC as output. Therefore, if the output of solar panel varies between $30 \mathrm{~V}$ to $60 \mathrm{~V}$, there will be no problem to make the inverter input $48 \mathrm{~V}$ DC as well as $220 \mathrm{~V}$ AC for connecting with the national grid.

\section{HOMER SIMULATION}

HOMER is a computer model that simplifies the task of de-signing distributed generation (DG) systems both on and offgrid. HOMER's optimization and sensitivity analysis algorithms allow us to evaluate the economic and technical feasibility of a large number of technology options and to account for variations in technology costs and energy re-source availability. HOMER can model both the technical and economic factors involved in the project. It can provide an important overview that compares the cost and feasibility of different configurations; then designers can use more specialized software to model the technical performance [10]. 
International Journal of Innovative Research in Electrical, Electronics, Instrumentation and Control Engineering

Vol. 9, Issue 7, July 2021

DOI 10.17148/IJIREEICE.2021.9721

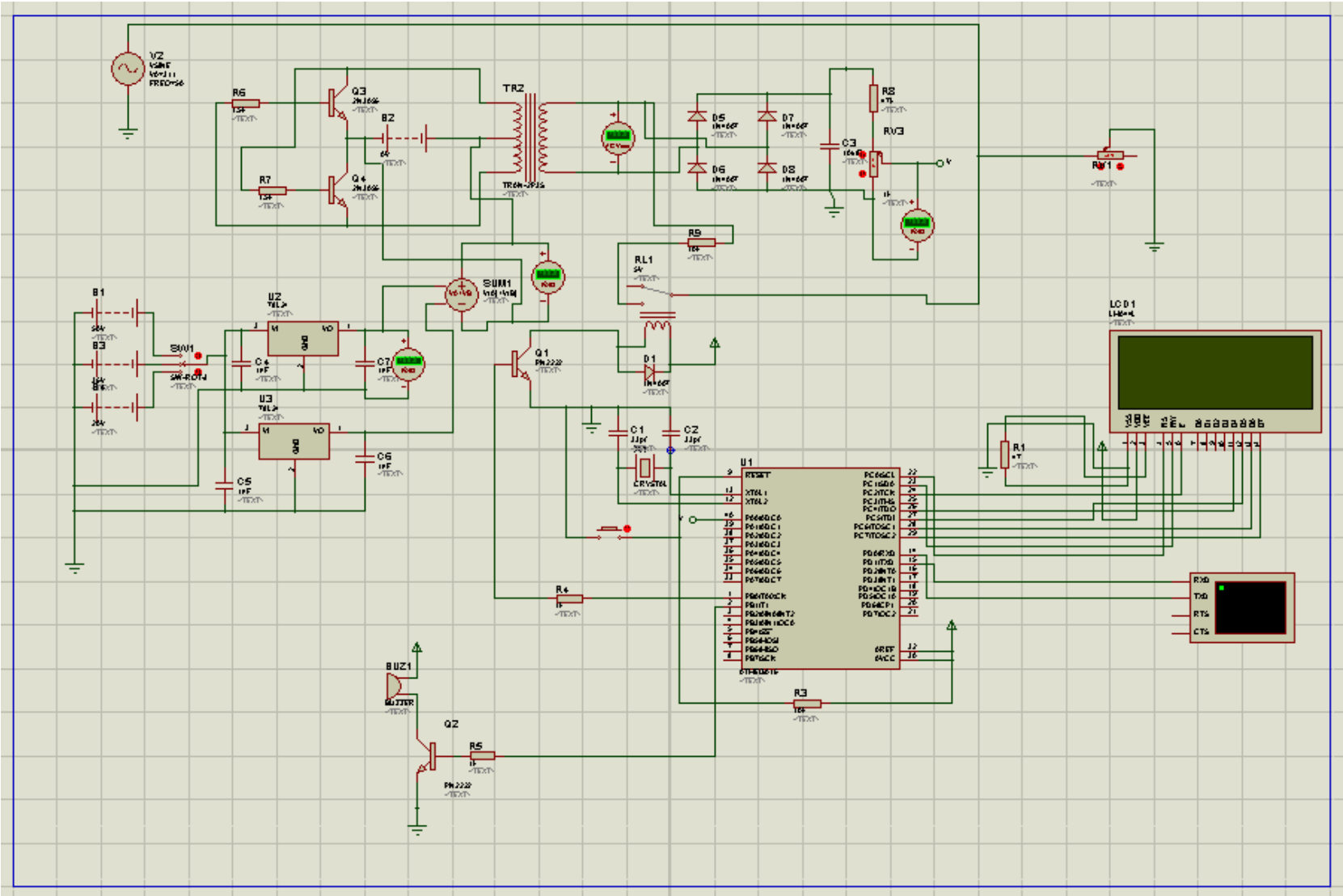

Fig. 13 Design of a grid-tie inverter in Proteus.

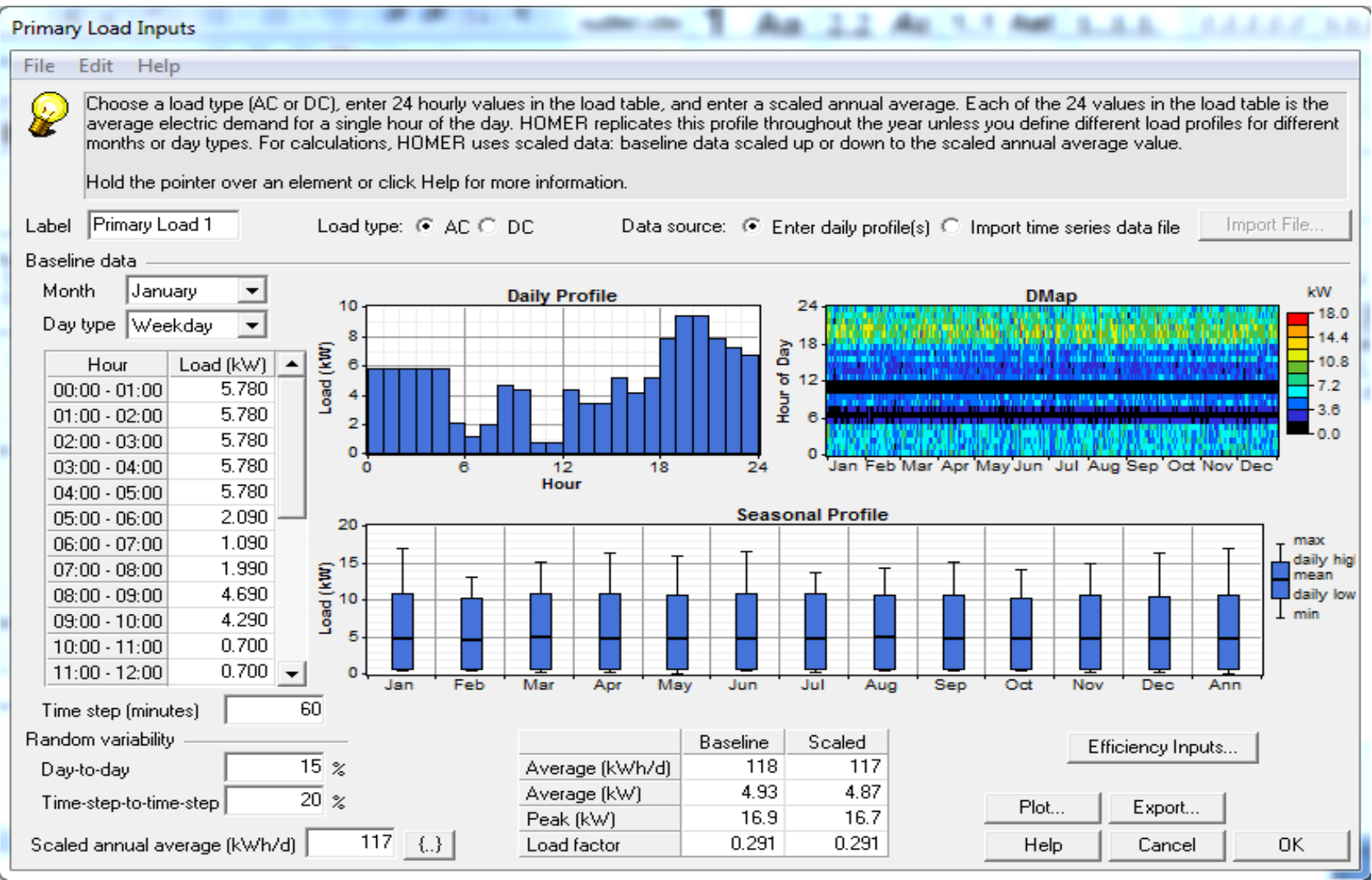

Fig. 14 Primary load input (in HOMER). 
International Journal of Innovative Research in

Electrical, Electronics, Instrumentation and Control Engineering

Vol. 9, Issue 7, July 2021

DOI 10.17148/IJIREEICE.2021.9721

\section{A. Primary Load and DMap}

Primary load is electrical load that the system must meet immediately in order to avoid unmet load. In each time step, HOMER dispatches the power-producing components of the system to serve the total primary load [3].Primary Load Inputs window of Homer is shown in Fig. 14. A DMap (data map) is a type of graph showing one year of time series data. With time of day on one axis and day of the year on the other, each time steps of the year is represented by a rectangle, which is colored according to the data value for that hour. The DMap format often allows us to see daily and seasonal patterns more easily than a simple time series plot. DMap appears in primary load inputs window.

\section{B. PV Input}

PV input is to provide the PV information for instance capital, replacement, operation \& maintenance cost and also the sizes of PV etc. When specifying the capital and replacement costs, it is necessary to account for all costs associated with the PV subsystem, which includes PV panels, mounting hardware, tracking system, control system (maximum power point tracker), wiring and installation.

\section{Battery Input}

Battery input is used to choose the type of battery, specifying its costs including capital, replacement, operation \& maintenance cost and the sizes etc.

\section{Converter Input}

Any system that contains both AC and DC elements requires a converter. This converter input allows defining the cost curve of the converter and choosing the sizes for HOMER to consider as it searches for the optimal system [3].

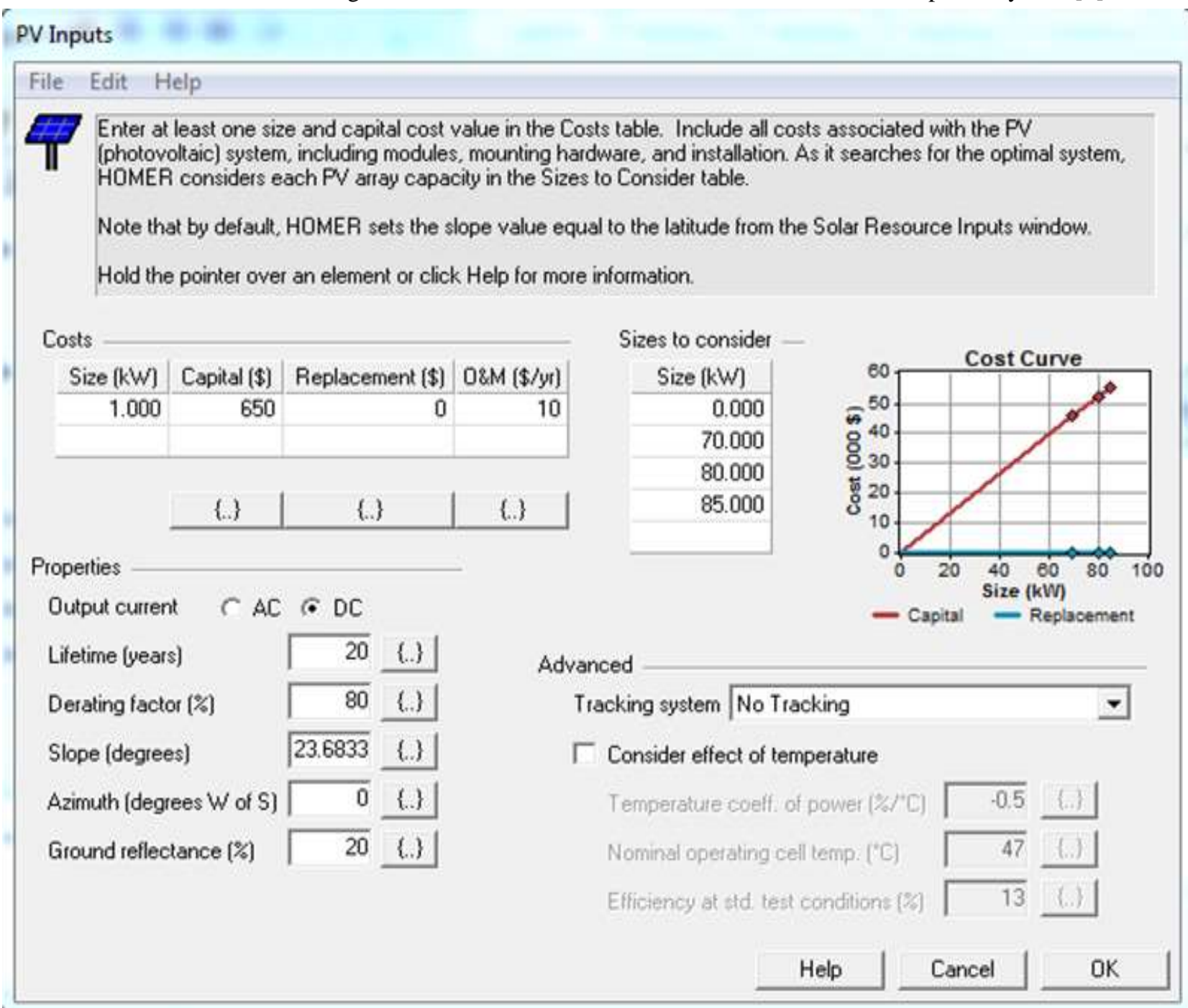

Fig. 15 PV input (in HOMER). 
International Journal of Innovative Research in Electrical, Electronics, Instrumentation and Control Engineering

Vol. 9, Issue 7, July 2021

DOI 10.17148/IJIREEICE.2021.9721

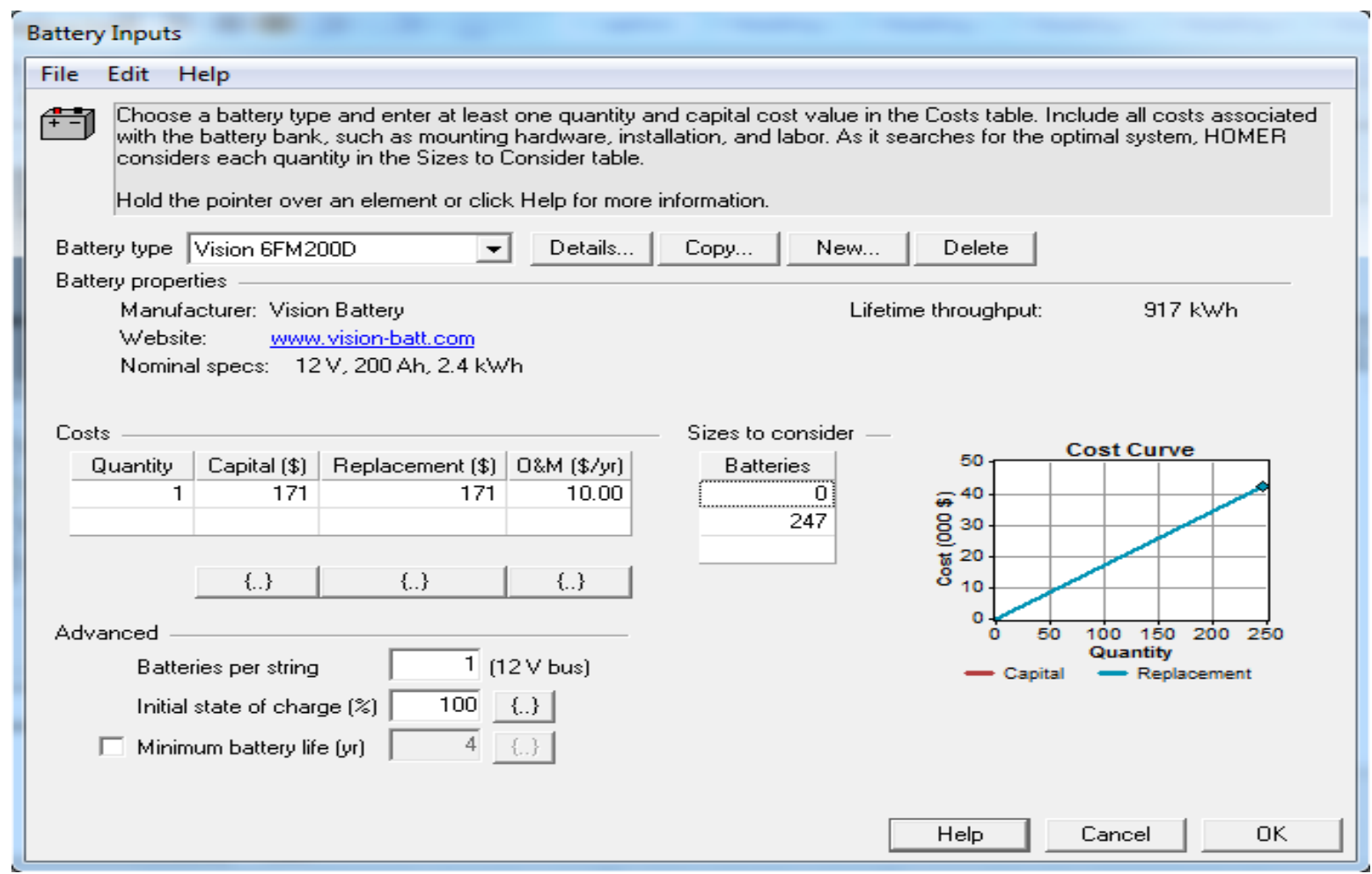

Fig. 16 Battery input (in HOMER).

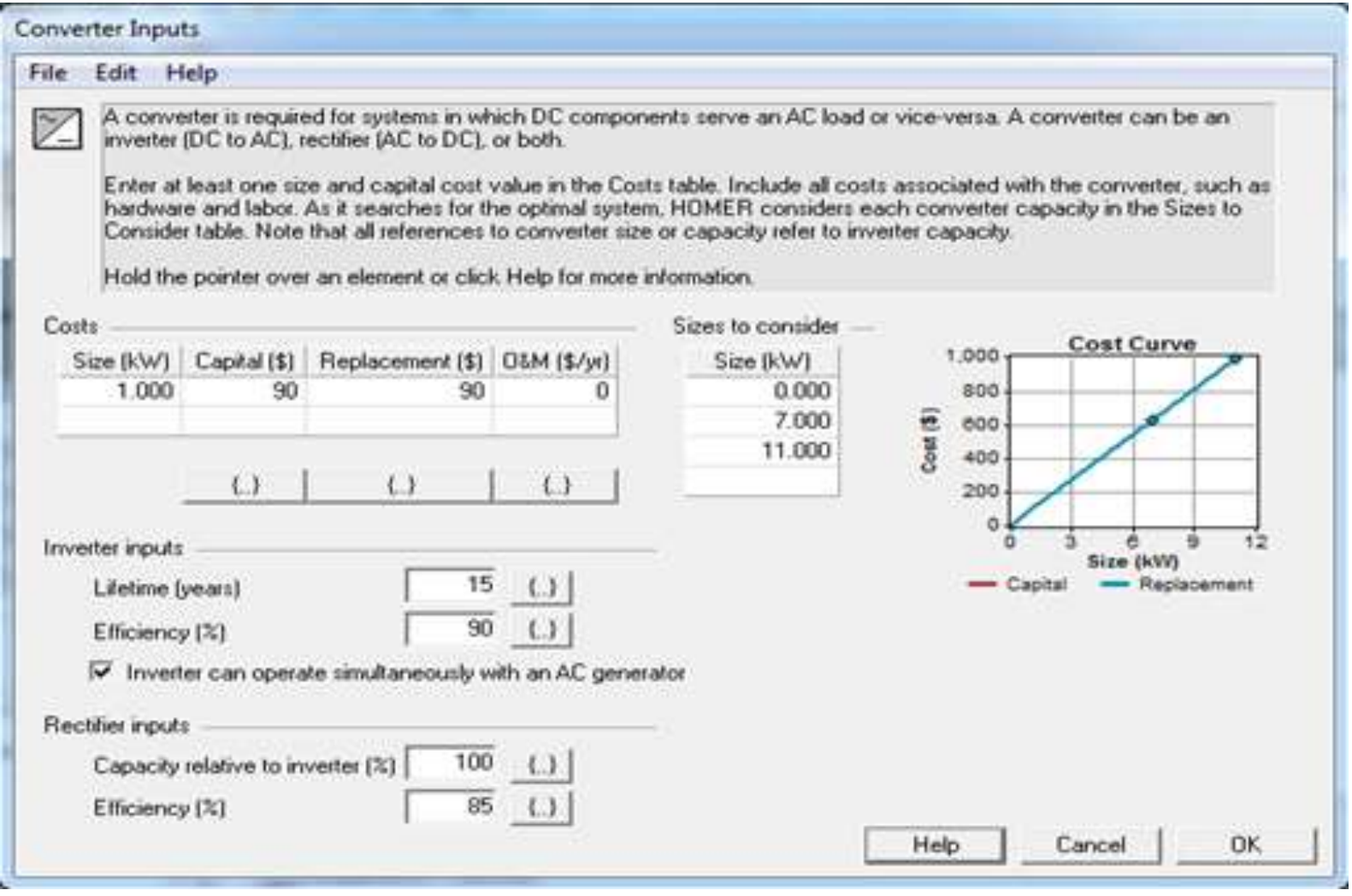

Fig. 17 Converter input (in HOMER).

E. Generator Input

Generator input is used to specifying its costs including capital, replacement, operation \& maintenance cost and the sizes. 
International Journal of Innovative Research in

Electrical, Electronics, Instrumentation and Control Engineering

Vol. 9, Issue 7, July 2021

\section{DOI 10.17148/IJIREEICE.2021.9721}

F. Solar Resource Input

Solar Resource Input is used to give input the daily solar radiation data. Homer uses solar resource inputs to calculate PV array power for each hour of the year.

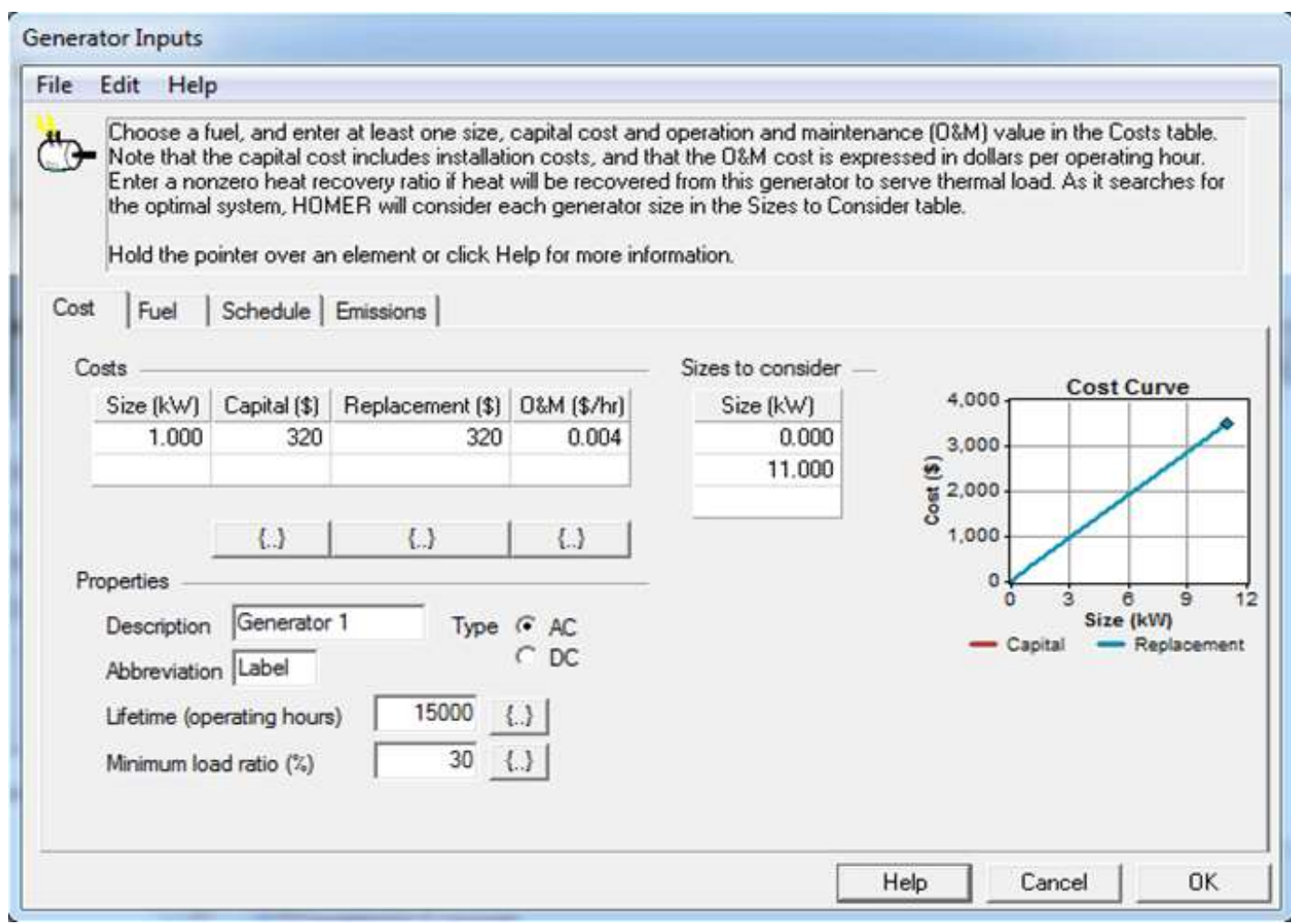

Fig. 18 Generator input (in HOMER).

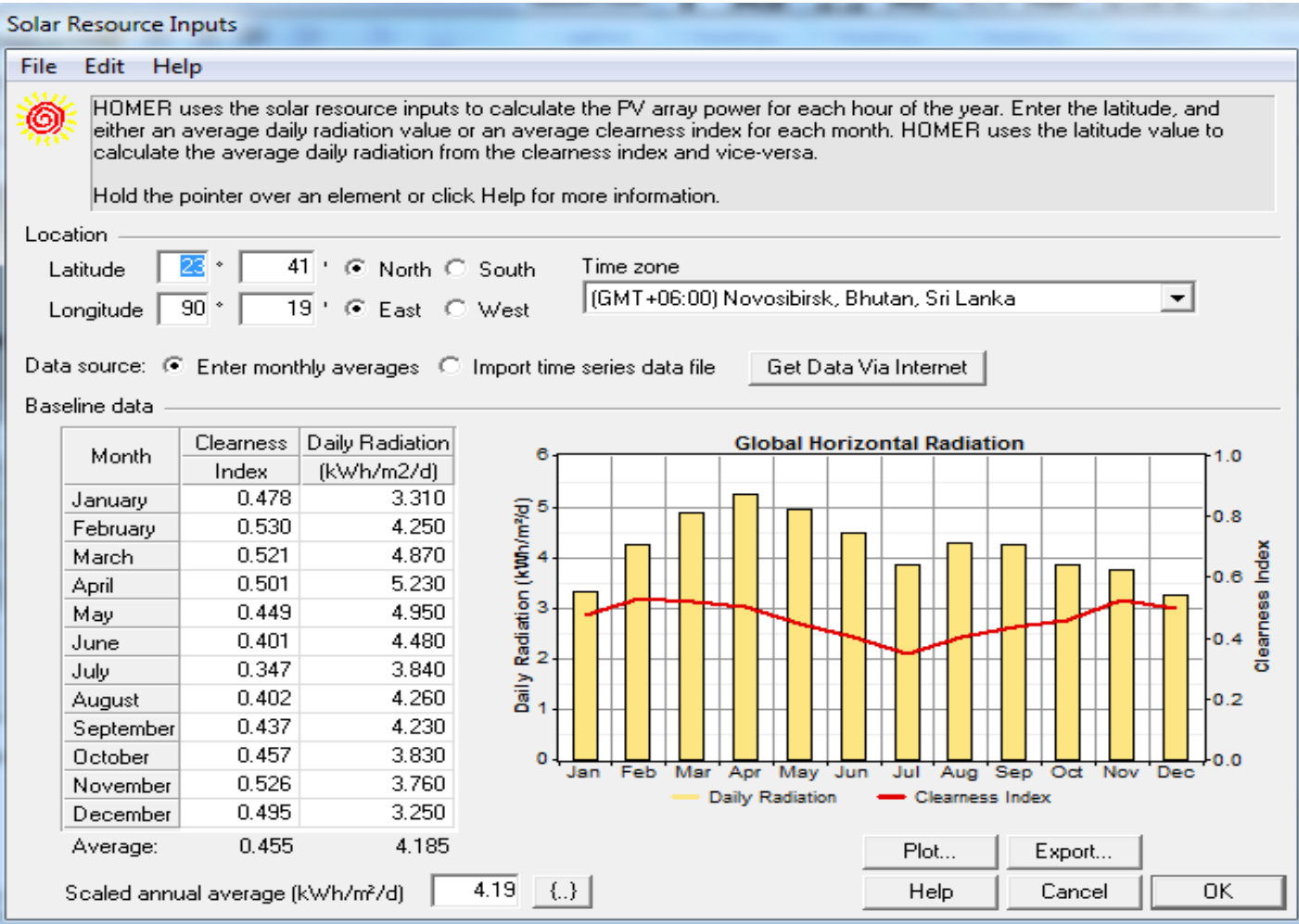

Fig. 19 Solar resource input (in HOMER). 
International Journal of Innovative Research in Electrical, Electronics, Instrumentation and Control Engineering

Vol. 9, Issue 7, July 2021

DOI 10.17148/IJIREEICE.2021.9721

G. Diesel Input

Diesel input is used to provide information about the fuel.

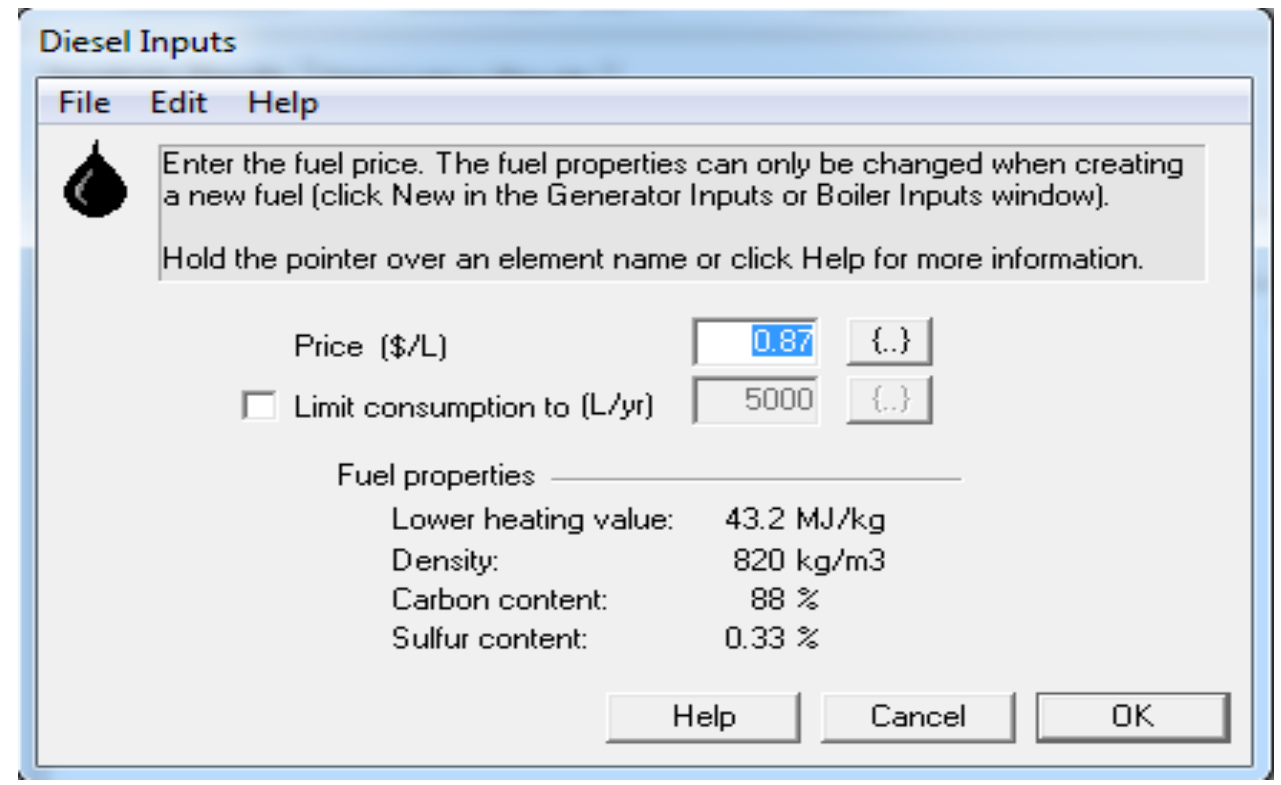

Fig. 20 Diesel input (in HOMER).

\section{COST ANALYSIS USING HOMER SOFTWARE}

Homer software has been used to analyze the cost of the proposed hybrid AC mini-grid system. The simulation is done for both $48 \mathrm{~V}$ and $220 \mathrm{~V}$ system voltage as well as full and thirty percent battery backup. A possible system has been found by analyzing the simulation. Load data was given for one day as the primary load input in the Hummer simulation. From the data, the software generated daily load profile, seasonal load profile, scaled annual average and much more. All their capital expenditure, replacement cost, operation and maintenance cost as well as panel size, battery size, generator size, converter size were also given as input. In addition, solar resources (daily solar radiation), fuel prices etc. have been provided as inputs. Solar PV and battery numbers are taken from the Table II to find the Cost of Energy (COE) for both $48 \mathrm{~V}$ and $220 \mathrm{~V}$ systems. In both cases, the PV module rating is considered $12 \mathrm{~V}, 3.5 \mathrm{~A}$ and the battery rating is $12 \mathrm{~V}$, 200Ah.Homer simulation window for both system voltage with $100 \%$ and $30 \%$ battery backup are shown in following figures.

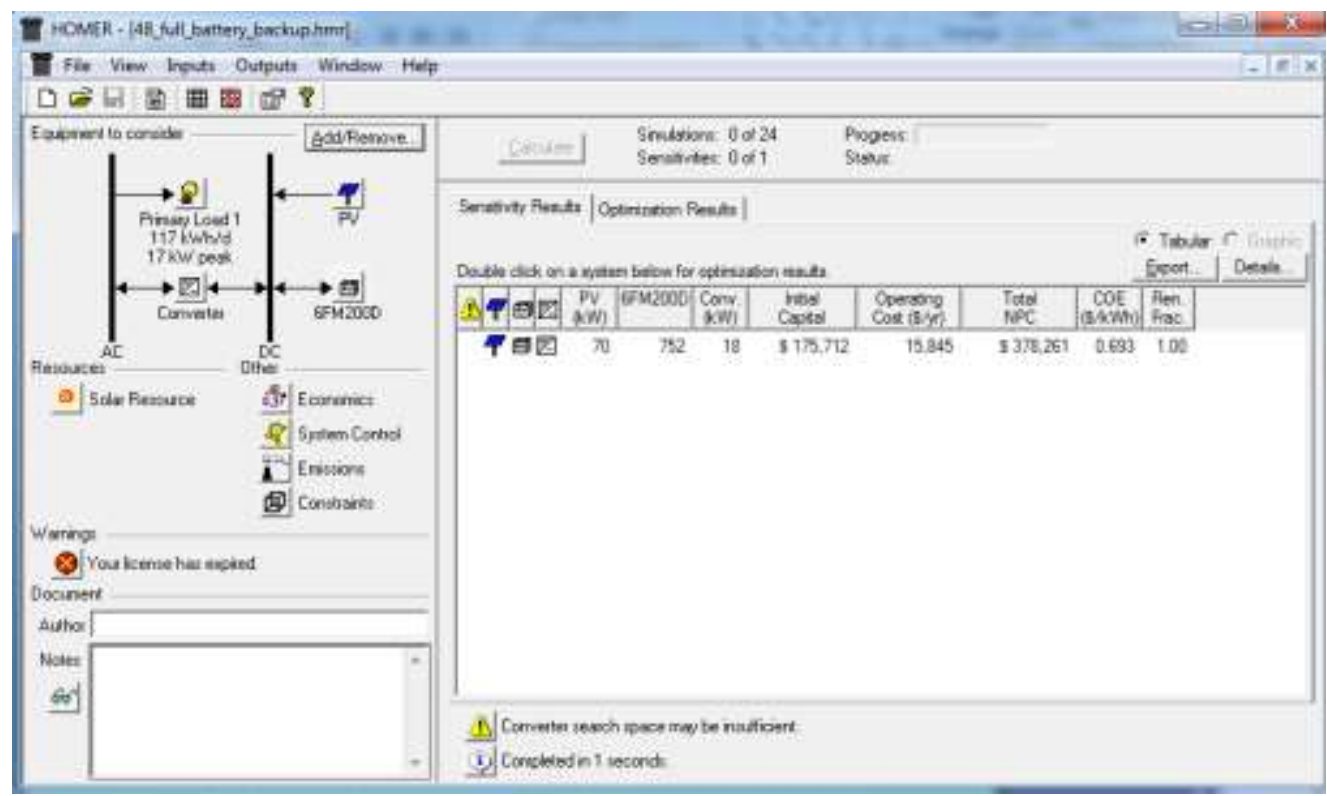

Fig. 21 Homer simulation for $48 \mathrm{~V}$ system voltage with $100 \%$ battery backup. 
International Journal of Innovative Research in Electrical, Electronics, Instrumentation and Control Engineering

Vol. 9, Issue 7, July 2021

DOI 10.17148/IJIREEICE.2021.9721

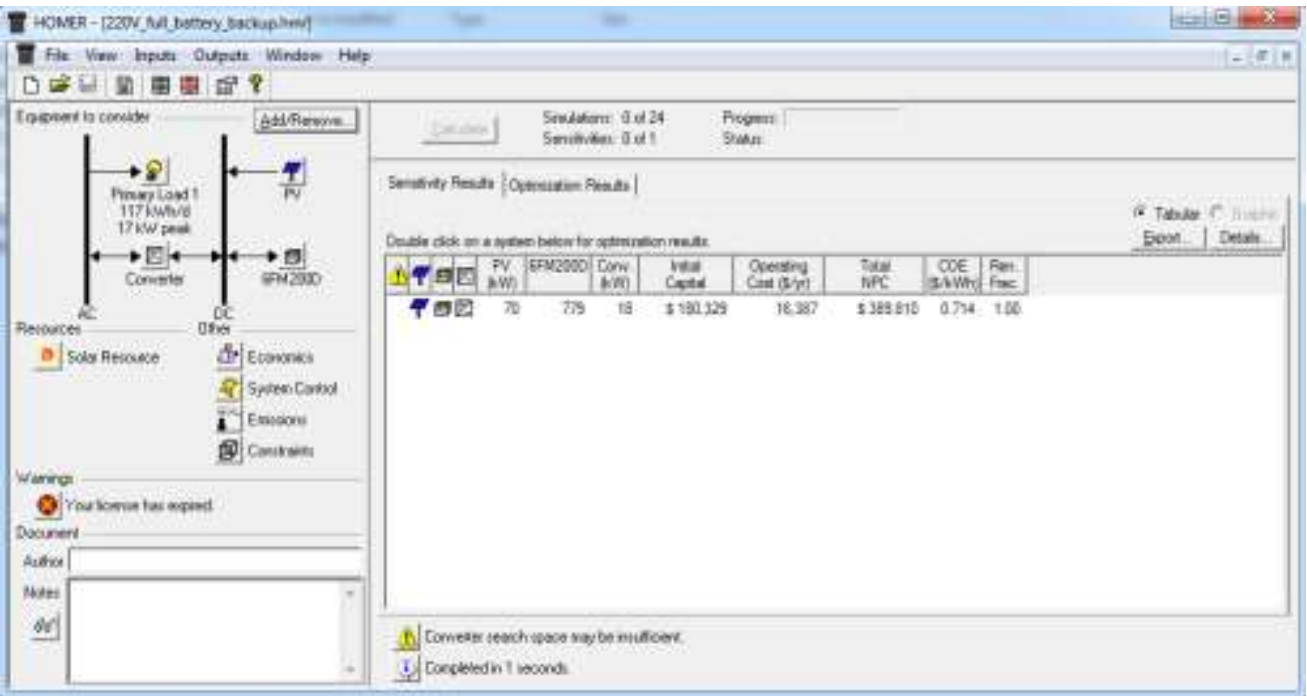

Fig. 22 Homer simulation for $220 \mathrm{~V}$ system voltage with $100 \%$ battery backup.

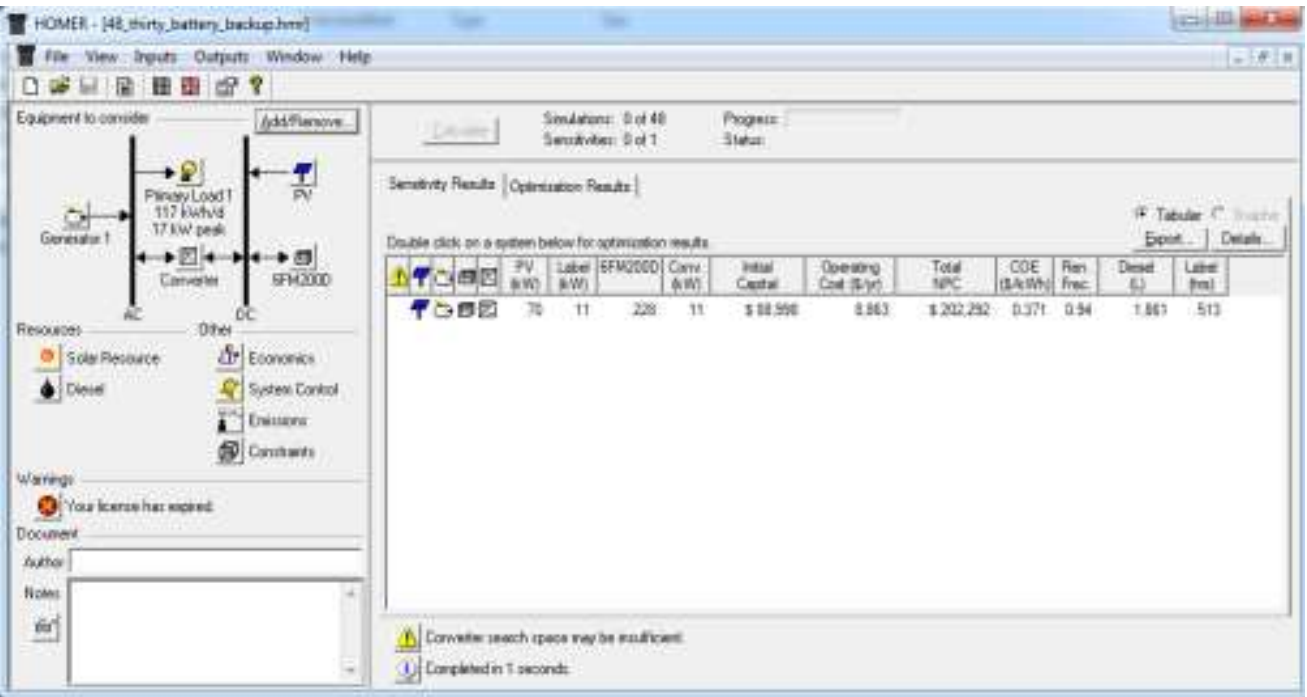

Fig. 23 Homer simulation for $48 \mathrm{~V}$ system voltage with $30 \%$ battery backup.

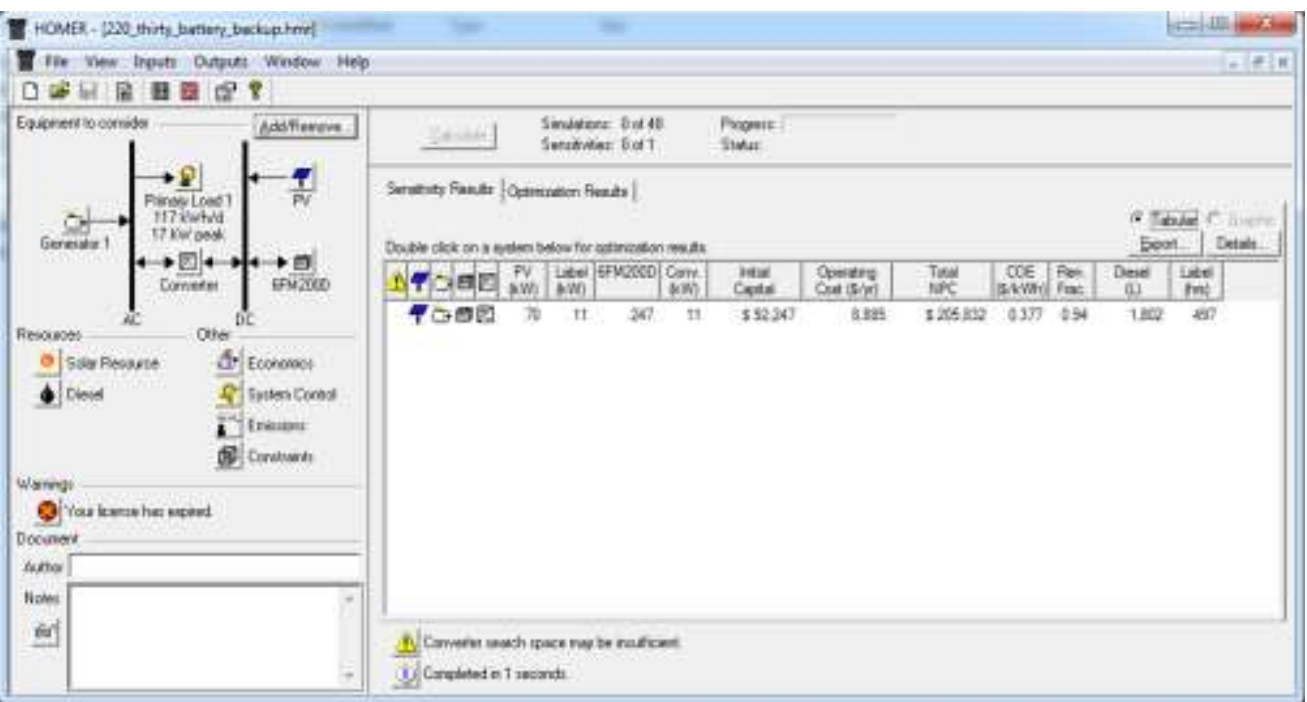

Fig. 24 Homer simulation for $220 \mathrm{~V}$ system voltage with $30 \%$ battery backup. 
International Journal of Innovative Research in Electrical, Electronics, Instrumentation and Control Engineering

Vol. 9, Issue 7, July 2021

DOI 10.17148/IJIREEICE.2021.9721

The summery of Cost of Energy (COE) found from the above Homer simulation window for the both system voltage of $48 \mathrm{~V}$ and $220 \mathrm{~V}$ is given in Table II.

TABLE II COE FOR THE 48V AND 220V SYSTEM

\begin{tabular}{|c|c|c|}
\hline System Voltage & COE for 100\% battery backup & COE for 30\% battery backup \\
\hline $48 \mathrm{~V}$ & 0.693 dollar/KWh & $0.371 \mathrm{dollar} / \mathrm{KWh}$ \\
\hline $220 \mathrm{~V}$ & 0.714 dollar/KWh & 0.377 dollar/KWh \\
\hline
\end{tabular}

\section{RESULTS}

This AC mini grid system has six important parts, namely charge controller design, transmission line parameter de-sign, digital energy meter design and implementation, grid tie inverter, power line carrier communication and cost analysis for each unit of power. This paper deals with the above essential parts to design a reliable and feasible AC mini grid for remote area of Bangladesh.

\section{A. Designing a Charge Controller}

The Solar Charge Controller has been successfully designed in a simulation that has the qualities of high voltage disconnection, low voltage disconnection and specific gravity status, and has yielded accurate results.

\section{B. Transmission Line Parameters}

Results for a $1000 \mathrm{~m}$ long transmission line

1. Conductor name: Tharashar

2. Line loss: $184.57 \mathrm{~W} / \mathrm{km}$

3. Resistance $=0.0266 \mathrm{ohm} / \mathrm{km}$ at $270 \mathrm{C}$

C. Designing an Energy Meter

Results from the digital energy meter are followings both in software and in hardware.

1. Cumulative energy display in $\mathrm{kWh}$

2. Disconnection due to over load.

3. Disconnection due to short circuit

4. Communication between energy meter and LDC

\section{Designing Power Line Carrier Communication}

Results from the power line carrier communication in simulation are as follows:

1. Amplitude modulation/demodulation.

2. Power line carrier circuit.

\section{E. Designing Grid tie Inverter}

Results from the grid tie inverter are followings in simulation.

$1.48 \mathrm{~V}$ fixed voltage regulation ranges from $30 \mathrm{~V}$ to $60 \mathrm{~V}$

2. Disconnection of the grid out of this range.

\section{F. COE Analysis}

From the Table II, it is found that the system voltage $48 \mathrm{~V}$ with $30 \%$ battery backup is more feasible than $100 \%$ battery backup system. The cost of energy (COE) for the proposed system is 0.371 dollar/kWh. In solar home system or solar mini grid system, battery is one of the most important factors, which is directly responsible for increasing the initial installation cost. Therefore, rural people could not be able to afford the PV system. Considering the installation cost, cost analysis has been done for two different battery backup systems. For the system voltage 48V with $100 \%$ battery backup, the cost of energy is 0.693 dollar/KWh, which is very high in compare to $30 \%$ battery backup system.

\section{CONCLUSION}

Mini grids are becoming more and more popular in different off grid areas of Bangladesh as most areas still do not have grid connection. Part of the work on this project was a sur-vey, which revealed that electricity is very badly needed for the development of the country as well as rural areas. It was noticed that rural people are more interested in using AC load instead of DC load. Therefore, an AC mini grid system has been designed for the remote areas of Madaripur district 
International Journal of Innovative Research in Electrical, Electronics, Instrumentation and Control Engineering

Vol. 9, Issue 7, July 2021

\section{DOI 10.17148/IJIREEICE.2021.9721}

in Bangladesh. In addition, the AC mini grid that has been designed is a total package with various necessary parts. These parts make the system more feasible and reliable. Cost analysis by Homer Software is a revolution in mini grid systems. Using it, the budget of any project can be easily estimated. Necessary parts like energy meter, charge controller, transmission line, power line communication and grid tie inverter increase the reliability of hybrid AC mini grid. Considering the numerous benefits, this designed AC mini grid system can be a great solution for the rural people of Bangladesh.

\section{REFERENCES}

[1]. A. Amin, A. Sultana, J. Hasan, M. T. Islam and F. Khan, "Solar home system in Bangladesh: Prospects, challenges and constraints," 2014 3rd International Conference on the Developments in Renewable Energy Technology (ICDRET), Dhaka, 2014, pp. 1-5, doi: 10.1109/ICDRET.2014.6861704.

[2]. Google maps, "Babu molla kandi, shipchar”. Available: https://www.google.com.bd/maps/place/Babu+Molla+kandi/@23.3959617, 90.1901672, $\quad 716 \mathrm{~m} /$ data $=! 3 \mathrm{~m} 2 ! 1 \mathrm{e} 3 ! 4 \mathrm{~b} 1 ! 4 \mathrm{~m} 5 ! 3 \mathrm{~m} 4 ! 1 \mathrm{~s} 0 x 37559 \mathrm{dd} 001313505: 0 x 8670 \mathrm{c} 4107 \mathrm{~b} 7 \mathrm{c} 4571 ! 8 \mathrm{~m} 2 ! 3 \mathrm{~d} 23.3959617 ! 4 \mathrm{~d} 90.1923559$ (accessed April 27, 2020)

[3]. Homer Energy, "HOMER Pro". Avaible: https://www.homerenergy.com/products/pro/index. html (accessed April 28, 2020)

[4]. Bala, B., \& Siddique, S. A. (2009). Optimal design of a PV-diesel hybrid system for electrification of an isolated island - Sandwip in Bangladesh using genetic algorithm. Energy for Sustainable Development, 13(3), 137-142. doi:10.1016/j.esd.2009.07.002

[5]. Amin, N., Yi, L. Z., \& Sopian, K. (2009). Microcontroller based smart charge controller for standalone solar photovoltaic power systems. 2009 34th IEEE Photovoltaic Specialists Conference (PVSC). doi:10.1109/pvsc.2009.5411210

[6]. Transmission Conductors - A review of the design and selection criteria by Southwire Communications (01-31-2003) F. Ridley Thrash, Jr. Chief Engineer, Overhead Conductors Wire \& Cable Technology Group Southwire Company

[7]. Arif, A., Al-Hussain, M., Al-Mutairi, N., Al-Ammar, E., Khan, Y., \& Malik, N. (2013). Experimental study and design of smart energy meter for the smart grid. 2013 International Renewable and Sustainable Energy Conference (IRSEC). doi:10.1109/irsec.2013.6529714

[8]. M. Zimmermann and K. Dostert, “A multipath model for the power line channel,” IEEE Trans. Commun., vol. 50, no. 4, pp. 553-559, Apr. 2002.

[9]. Mohamed, Y. A.-R. I. (2011). Mitigation of Dynamic, Unbalanced, and Harmonic Voltage Disturbances Using Grid-Connected Inverters With \$LCL\$ Filter. IEEE Transactions on Industrial Electronics, 58(9), 3914-3924. doi:10.1109/tie.2010.2098372

[10]. Amutha, W. M., \& Rajini, V. (2016). Cost benefit and technical analysis of rural electrification alternatives in southern India using HOMER Renewable and Sustainable Energy Reviews, 62, 236-246. doi:10.1016/j.rser.2016.04.042 